\title{
Hubungan Dimensi Kepribadian The Big Five Personality dengan Penyesuaian Diri Mahasiswa Asing di Universitas Udayana
}

\author{
Demira Shaifa dan Supriyadi \\ Program Studi Psikologi, Fakultas Kedokteran, Universitas Udayana \\ demirashaifa@yahoo.com
}

\begin{abstract}
Abstrak
Mahasiswa asing rentan mengalami permasalahan penyesuaian diri dan menghadapi berbagai situasi yang membuat stres ketika mereka melanjutkan pendidikan di luar negeri (Yusoff \& Chelliah, 2006). Bagaimana mereka menghadapi permasalahan penyesuaian diri tergantung dari kepribadian unik mereka masing-masing (Ward,Leong, \& Low, 2004). Penelitian kuantitatif dengan pendekatan korelasional ini bertujuan untuk mengetahui hubungan antara dimensi kepribadian pada The Big Five Personality dengan penyesuaian diri mahasiswa asing di Universitas Udayana.

Seratus empat puluh lima mahasiswa asing dari berbagai negara yang menetap di Bali maksimal satu tahun dan sedang mengikuti perkuliahan di Universitas Udayana menjadi subjek dalam penelitian ini. Kepribadian diukur menggunakan The Big Five Inventory (reliabilitas $=0,946$ ) dan penyesuaian diri diukur menggunakan Sojourner Adjustment Measure yang dimodifikasi dari versi Pedersen (2011) (reliabilitas $=0,785$ ). Data memiliki persebaran normal, yaitu $\mathrm{p}=0,776$ untuk kepribadian dan $\mathrm{p}=0,199$ untuk penyesuaian diri serta memiliki model linier $(\mathrm{p}=$ $0,000)$.

Korelasi parsial digunakan untuk melakukan analisis. Hasil analisis menunjukkan bahwa terdapat hubungan yang positif dan signifikan antara agreeableness $(r=0,285, p<0,05)$ dan openness to new experience $(r=0,136, p<0,05)$ dengan penyesuaian diri mahasiswa asing di Universitas Udayana. Sementara itu, tidak ditemukan hubungan yang signifikan antara dimensi kepribadian extraversion, conscientiousness, dan neuroticism dengan penyesuaian diri mahasiswa asing di Universitas Udayana.
\end{abstract}

Kata kunci: kepribadian, The Big Five Personality, penyesuaian diri, mahasiswa asing.

\begin{abstract}
International students are vulnerable to have adjustment issues and faced stressful events when they study abroad (Yusoff \& Chelliah, 2006). How they cope with adjustment issues depends on their unique personality (Ward, Leong, \& Low, 2004). This quantitative research with correlational approach is aimed to find out the relationship between personality dimensions from The Big Five Personality and adjustment of international students in Udayana University.

One hundred and forty five international exchange students across nations who stayed in Bali for maximum of one year and have a course in Udayana University became subject of this research. Personality was measured by The Big Five Inventory (reliability $=0,946$ ) and sojourner adjustment was measured by Sojourner Adjustment Measure that modified from Pedersen's (2011) version (reliability $=0,785$ ). Data has a normal distribution, those are $\mathrm{p}=0,776$ for personality and $\mathrm{p}=0,199$ for adjustment and also has a linear model $(\mathrm{p}=0,000)$.

Partial correlation was performed to do the analysis. The result indicates that there are positive and significant relationship between agreeableness $(r=0,285, \mathrm{p}<0,05)$ and openness to new experience $(r=0,136, p<0,05)$ towards adjustment of international students in Udayana University. However, there are no significant relationship found in extraversion, conscientiousness, and neuroticism towards adjustment of international students in Udayana University.
\end{abstract}

Keywords: personality, The Big Five Personality, sojourner adjustment, international students. 


\section{LATAR BELAKANG}

Banyaknya negara dengan seluruh atribut di dalamnya, seperti masyarakat, pola hidup masyarakat, serta nilai-nilai masyarakat menyebabkan beragamnya nilai-nilai dalam suatu negara di seluruh dunia. Nilai-nilai itu lama kelamaan menjadi sebuah budaya yang mengakar pada tiap individu dalam negara tersebut dan menjadi ciri khas dari masing-masing negara. Pada tahun-tahun sebelumnya, perjalanan ke tempat yang lebih jauh dari daerah asal sangat jarang dilakukan karena sulit dan terbatasnya akses transportasi. Seiring dengan munculnya era globalisasi yang ditandai dengan perkembangan teknologi dan transportasi yang pesat, hal tersebut mulai mengalami perubahan (Sumer, 2009). Pesatnya perkembangan teknologi dan transportasi ini akhirnya menyebabkan banyak orang dari negara satu berkunjung ke negara lainnya. Secara otomatis, budaya dari individu yang bepergian ke luar dari negara asalnya akan bertemu dengan budaya dari negara tujuan sehingga terjadilah pertukaran budaya.

Saat ini, individu mendapatkan berbagai nilai-nilai dari budaya yang berbeda-beda karena meningkatnya kontak antar individu berbeda budaya, baik itu didapatkan oleh pendatang maupun masyarakat asli yang menerima pendatang tersebut di daerahnya (Sumer, 2009). Individu yang bepergian ke negara lain untuk tujuan tertentu dalam jangka waktu sementara disebut sojourner (Church, 1982). Sojourner bepergian ke negara lain dengan berbagai kepentingan yang berbeda-beda, seperti dalam bidang ekonomi, sosial politik, militer, pendidikan, dan lain sebagainya. Salah satu bidang yang saat ini sedang mengalami perkembangan yang sangat pesat adalah bidang pendidikan.

Pendidikan sudah tidak lagi hanya berkisar dalam cakupan nasional saja, tetapi individu kini sudah mulai banyak yang menempuh pendidikan dalam cakupan internasional. Sojourner yang memiliki kepentingan dalam bidang pendidikan internasional secara tidak langsung mengalami peningkatan yang signifikan. Sojourner yang merupakan mahasiswa asing ini mengalami peningkatan $12 \%$, dan pada tahun 2009 jumlah mahasiswa di seluruh dunia mencapai 3,43 juta jiwa (UNESCO, 2009). Jumlah mahasiswa asing ini meningkat lebih dari 75\% sejak tahun 2000 (BBC News, 2009). Tujuan internasional yang paling diminati oleh mahasiswa asing sebesar lebih dari 90\% ialah Amerika Serikat, diikuti oleh Inggris, Jerman, Prancis, dan Australia (Verbik, Hobsons, \& Lasanowski, 2007). Di Amerika Serikat saja, terdapat 691.000 orang mahasiswa asing, dengan negara asal kebanyakan dari benua Asia seperti Cina (lebih dari 440.000 orang), India, dan Korea Selatan (Institute of International Education, 2009).

Awalnya, negara tujuan mahasiswa asing dominan berada di benua Amerika, Eropa, dan Australia. Tetapi dengan laju pendidikan dunia yang semakin dinamis, negara-negara di benua Asia juga sudah mulai mengembangkan bidang pendidikannya hingga setara dengan kualitas pendidikan yang terdapat di benua Amerika, Eropa, maupun Australia. Negara tujuan yang paling diminati di benua Asia adalah Cina (45\%), diikuti oleh Jepang (15\%), Korea Selatan (12\%), Vietnam, Malaysia, dan Indonesia (7\%) (BBC News, 2009). Sedangkan jumlah mahasiswa asing di Indonesia, terutama di Bali, khususnya di Universitas Udayana, ialah sebanyak 2300 orang sampai tahun 2008, yang berasal dari Asia-Pasifik (Malaysia, Jepang, Korea, Australia, Timor Leste, dan Maroko), dan juga dari benua Eropa (Jerman, Norwegia, dan Swedia), serta dari Amerika Serikat (International Office of Udayana University, 2008).

Mahasiswa asing yang melanjutkan pendidikannya di Universitas Udayana, terutama di Universitas Udayana berasal dari Malaysia, Jepang, Korea, Australia, Timor Leste, Maroko, Jerman, Norwegia, Swedia, dan Amerika Serikat (International Office of Udayana University, 2008). Dari negara-negara tersebut, terdapat beberapa negara yang memiliki latar belakang budaya yang sama sekali berbeda dengan budaya yang ada di Bali. Budaya Bali yang merupakan budaya kolektivisme, dimana masyarakat Bali sangat mementingkan interaksi dengan orang lain serta mementingkan kepentingan kelompoknya dibandingkan dengan kepentingan individu sangat berbeda dengan budaya mahasiswa asing yang berasal dari negara berbudaya individualisme seperti Australia, Jerman, Norwegia, Swedia, dan Amerika Serikat. Mahasiswa asing yang berasal dari negara dengan latar belakang budaya individualisme akan menemui beberapa hambatan dalam proses penyesuaian diri di Bali karena budaya yang dimilikinya saling bertolak belakang. Mahasiswa asing yang melanjutkan pendidikannya ke negara dengan latar belakang budaya berbeda akan menjumpai permasalahan penyesuaian diri pada enam bulan pertama kepindahan ke negara tujuan. Individu akan menyesuaikan diri apabila dihadapkan pada perubahan baik di dalam diri individu sendiri maupun lingkungannya. Penyesuaian diri yang dilakukan oleh individu berfungsi untuk mencapai hubungan yang memuaskan dengan orang lain dan juga lingkungan sekitar individu tersebut berada (Atwater, 1983). Penyesuaian diri yang dilakukan oleh mahasiswa asing ini disebabkan oleh adanya perbedaan nilai-nilai budaya negara asalnya dengan negara tujuan. Mahasiswa asing yang melanjutkan pendidikannya ke negara dengan budaya yang jauh berbeda dari negara asalnya akan menemukan beberapa kesulitan. Kesulitan-kesulitan ini terjadi akibat adanya culture shock, yaitu proses awal dari masuknya individu ke lingkungan baru yang tidak familiar dengan lingkungannya sehari-hari (Pedersen, Neighbors, Larimer, \& Lee, 2011).

Culture shock terjadi karena nilai budaya yang dimiliki individu sangat berbeda dengan nilai budaya yang dimiliki oleh masyarakat dalam negara tujuan pendidikannya. 
Selain itu, kesulitan dalam menyesuaikan diri juga timbul akibat dari diskriminasi ras, masalah bahasa, kesulitan akomodasi, pantangan makanan, kesulitan finansial, serta timbulnya salah pengertian, dan kesepian (Lin \& Yi, 1997). Tuntutan akademis yang tinggi serta tantangan untuk menyesuaikan diri pada budaya baru juga membuat proses mahasiswa asing dalam menyesuaikan diri menjadi lebih rapuh dan beresiko (Paige, 1990).

Mahasiswa asing yang berada di negara dengan budaya berbeda dari negara asalnya akan mengalami kesulitan dalam beradaptasi dengan lingkungan baru, berinteraksi dengan orang-orang di lingkungan barunya, serta menerima nilai-nilai baru yang terdapat dalam negara tersebut. Kesulitan adaptasi yang dihadapi oleh para mahasiswa asing dapat dilihat dari enam aspek dalam Sojourner Adjustment Measure (Pedersen, Neighbors, Larimer, \& Lee, 2011), yang tergolong ke dalam faktor positif dan faktor negatif dari penyesuaian diri. Faktor positif antara lain adalah interaksi sosial dengan masyarakat di negara tujuan, pemahaman budaya dan partisipasi di negara tujuan, pengembangan dan penggunaan bahasa negara tujuan, serta identifikasi budaya negara tujuan. Sedangkan faktor negatif antara lain adalah interaksi sosial dengan sesama individu dari negara asal dan homesickness, yaitu perasaan tidak nyaman di lingkungan baru dan ingin segera kembali ke lingkungan asal yang telah dikenal dengan baik.

Walaupun mayoritas individu dalam suatu negara memiliki nilai-nilai yang hampir serupa sehingga perilaku, pola pikir, dan moral masyarakat dalam negara itu terlihat sama, masing-masing individu tetap memiliki keunikannya sendiri. Setiap individu memiliki kognisi, afeksi, serta cara berperilaku yang berbeda dalam suasana dan waktu yang berbeda pula (Burger, 2008). Perbedaan itulah yang membuat individu satu dengan individu lainnya memiliki keunikan jika dibandingkan dalam masyarakat secara umum. Keunikan individu dapat timbul dari berbagai hal, terutama dalam hal kepribadian individu tersebut.

Berbagai definisi mengenai kepribadian terus berkembang karena tidak adanya satu teori tunggal yang dapat menjelaskan secara akurat mengenai kepribadian. Menurut Burger (2008), kepribadian adalah pola perilaku yang konsisten dan proses interpersonal yang terjadi dalam diri individu. Sedangkan menurut Feist dan Feist (2009), kepribadian didefinisikan sebagai pola watak yang relatif permanen dan karakter yang unik dimana keduanya memiliki konsistensi dan keunikan pada perilaku individu.

Salah satu teori kepribadian yang sering digunakan untuk menjelaskan kepribadian seseorang adalah The Big Five Personality. Dalam The Big Five Personality terdapat lima dimensi kepribadian, yaitu Extraversion (E), Agreeableness (A), Conscientiousness (C), Neuroticism (N), dan Openness to New Experience $(\mathrm{O})$.
Extraversion didefinisikan sebagai dimensi kepribadian yang enerjik terhadap dunia sosial dan material serta memiliki watak mudah bergaul, aktif, asertif, dan memiliki emosi yang positif. Agreeableness didefinisikan sebagai dimensi kepribadian yang berorientasi prososial pada orang lain serta memiliki watak altruisme, lemah lembut dan mudah percaya. Conscientiousness didefinisikan sebagai dimensi kepribadian dengan kontrol impuls yang memfasilitasi pengerjaan tugas dan juga perilaku goal-oriented seperti berpikir sebelum bertindak, mengikuti norma dan aturan, terorganisasi, serta memprioritaskan tugas. Neuroticism didefinisikan sebagai kepribadian dengan emosi negatif sehingga rentan mengalami kecemasan, depresi, sedih, agresif, dan lain-lain. Serta Openness to new experience yang didefinisikan sebagai dimensi kepribadian dengan daya imajinasi yang tinggi, orisinil, memiliki mental dan pengalaman hidup yang kompleks, serta berani mencoba hal-hal baru diluar kebiasaannya (Costa \& McCrae, 1992; John, 1990).

Seberapa baiknya tingkat penyesuaian diri mahasiswa asing akan sangat bergantung pada bagaimana masing-masing individu merespon setiap kondisi yang terjadi di lingkungan barunya. Mahasiswa asing dengan kepribadiannya masingmasing akan memiliki cara yang berbeda untuk menyesuaikan diri. Ward, Leong, dan Low (2004) dalam penelitian mereka yang berjudul Personality and sojourner adjustment: An exploration of the Big Five and the cultural fit proposition menunjukkan bahwa individu yang memiliki skor tinggi dalam extraversion, agreeableness, conscientiousness dan memiliki skor rendah dalam neuroticism akan lebih mudah dalam melakukan penyesuaian diri secara psikologis serta sosial.

Kepribadian conscientiousness dan agreeableness diasosiasikan dengan penyesuaian diri sosiokultural yang lebih baik, kesehatan psikologis, dan kesejahteraan individu. Selain itu, agreeableness penting untuk hubungan antara mahasiswa asing dengan masyarakat lokal. Sedangkan kepribadian neuroticism diasosiasikan dengan mudahnya individu mengalami depresi, penyalahgunaan zat dan obat-obatan, permasalahan dalam penyesuaian diri, dan lain-lain (Ward, Leong, \& Low, 2004). Maka dari itu, individu yang memiliki skor tinggi dalam neuroticism akan lebih rentan mengalami permasalahan dalam penyesuaian diri (Hogan, 1986). Kepribadian neuroticism dan extraversion berhubungan dengan penyesuaian diri psikologis dan sosiokultural, sedangkan kepribadian agreeableness dan conscientiousness dihubungkan dengan kesejahteraan individu dan juga penyesuaian diri sosiokultural (Ward, Leong, \& Low, 2004). Dalam penelitian yang dilakukan oleh Yusoff dan Chelliah (2010), terdapat beberapa hal yang terkait dengan penyesuaian diri yang dilakukan oleh mahasiswa asing. Status pernikahan mahasiswa asing, lamanya tinggal di negara tujuan, serta kelancaran berbahasa Inggris berhubungan secara positif dengan penyesuaian diri psikologis dan sosiokultural. 
Sedangkan usia, jenis kelamin, dan dukungan sosial berhubungan secara negatif dengan penyesuaian diri psikologis dan sosiokultural. Semakin tua usia mahasiswa asing serta semakin terbatasnya dukungan sosial yang dimiliki oleh mahasiswa asing membuat penyesuaian diri psikologis dan sosiokultural semakin sulit dilakukan.

Apabila dilihat dari dimensi kepribadian dalam The Big Five Personality, neuroticism, extraversion serta openness to new experiences dinyatakan memiliki hubungan negatif terhadap penyesuaian diri. Individu dengan skor dimensi neuroticism, extraversion, serta openness to new experiences yang tinggi akan membuat semakin sulitnya mahasiswa asing menyesuaikan diri. Sedangkan dimensi kepribadian conscientiousness dan agreeableness dinyatakan memiliki hubungan yang positif terhadap penyesuaian diri mahasiswa asing. Individu dengan skor yang tinggi pada dimensi conscientiousness dan agreeableness yang tinggi akan membuat semakin mudahnya mahasiswa asing menyesuaiakan diri.

Berdasarkan data-data yang telah dipaparkan di atas, peneliti tertarik untuk melihat bagaimana hubungan antara dimensi-dimensi kepribadian dalam The Big Five Personality dengan penyesuaian diri yang dimiliki mahasiswa asing di Universitas Udayana. Peneliti tertarik untuk mengetahui dimensi kepribadian apa sajakah yang paling memegang peranan dalam penyesuaian diri mahasiswa asing di Universitas Udayana dan seberapa besar hubungan antara dimensi kepribadian mahasiswa asing dengan penyesuaian diri di Universitas Udayana.

\section{METODE}

\section{Variabel dan definisi operasional}

Variabel penelitian adalah atribut maupun sifat memiliki variasi tertentu. Variasi dalam atribut ditetapkan oleh peneliti untuk dapat dipelajari sehingga dapat melakukan penarikan kesimpulan (Sugiyono, 2012). Pada penelitian ini, peneliti menetapkan tiga jenis variabel yaitu, variabel bebas, variabel tergantung, dan variabel kontrol. Variabel bebas dalam penelitian ini adalah kepribadian, variabel tergantung adalah penyesuaian diri, serta variabel kontrol adalah usia dan status pernikahan mahasiswa asing.

Definisi operasional dari variabel bebas, kepribadian adalah konsep pola perilaku yang ada dalam diri individu ketika menyesuaikan diri dalam lingkungan yang membuat individu memiliki keunikan tersendiri dibandingkan individu lainnya, serta bersifat konsisten dan dinamis. Salah satu teori kepribadian yang sering digunakan untuk menjelaskan dinamika kepribadian seseorang adalah The Big Five Personality yang dikembangkan oleh Costa dan McCrae (1985) dan dipopulerkan oleh Goldberg (1981). Dalam The Big Five Personality terdapat lima dimensi kepribadian, yaitu
Extraversion (E), Agreeableness (A), Conscientiousness (C), Neuroticism $(\mathrm{N})$, dan Openness to New Experience $(\mathrm{O})$. Kepribadian dapat diukur dengan menggunakan The Big Five Inventory (BFI) oleh John, Donahue, \& Kentle (1991) yang terdiri dari 44 aitem dengan model skala Likert 1-5 poin dari rentang sangat tidak setuju sampai sangat setuju yang telah teruji validitas serta reliabilitasnya.

Definisi operasional dari variabel tergantung, penyesuaian diri adalah proses yang terjadi ketika individu beradaptasi dengan lingkungan baru yang tidak familiar dibandingkan dengan lingkungan yang telah dialaminya dan bertujuan untuk mencapai kepuasan diri sendiri serta orang lain di lingkungan baru tersebut. Dalam penelitian ini, penyesuaian diri mahasiswa asing akan diukur menggunakan Sojourner Adjustment Measure (SAM) oleh Pedersen, Neighbors, Larimer, dan Lee (2011). Faktor-faktor dari Sojourner Adjustment Measure (SAM) terdiri dari faktor positif dan faktor negatif. Faktor-faktor positif SAM yaitu (1) interaksi sosial dengan masyarakat di negara tujuan, (2) pemahaman budaya dan partisipasi di negara tujuan, (3) pengembangan dan penggunaan bahasa negara tujuan, (4) identifikasi budaya negara tujuan. Sedangkan faktor-faktor negatif SAM yaitu interaksi sosial dengan sesama individu dari negara asal dan homesickness. Sojourner Adjustment Measure (Pedersen, Neighbors, Larimer, \& Lee, 2011) memiliki total aitem sebanyak 20 aitem dengan model skala Likert 1-7 poin dari rentang sangat tidak setuju sampai sangat setuju yang telah teruji validitas dan reliabilitasnya.

\section{Responden}

Populasi adalah wilayah generalisasi yang terdiri dari objek maupun subjek yang memiliki kualitas serta karakteristik tertentu yang telah ditetapkan oleh peneliti untuk dipelajari dan melakukan penarikan kesimpulan (Sugiyono, 2012). Populasi target dalam penelitian ini adalah seluruh mahasiswa asing. Sementara populasi terakses dalam penelitian ini adalah mahasiswa asing yang mengikuti program student exchange selama satu atau dua semester di Universitas Udayana.

Sampel merupakan bagian dari jumlah dan karakteristik yang dimiliki oleh populasi tersebut (Sugiyono, 2012). Dalam penelitian ini, sampel yang digunakan adalah mahasiswa asing di Universitas Udayana yang berasal dari Jerman, Cina, Korea, Swedia, Austria, Rusia, Lithuania, Prancis, Italia, Spanyol, Republik Ceko, Finlandia, Jepang, dan Norwegia yang didapatkan melalui teknik purposive sampling, yaitu teknik pengambilan sampel dengan pertimbangan tertentu (Sugiyono, 2012).

Kriteria sampel yang akan diambil untuk penelitian ini akan mengikuti kriteria inklusi sampel. Kriteria inklusi dalam penelitian ini adalah subjek yang mengikuti program 
student exchange yang mengikuti program pendidikan di Universitas Udayana dengan lamanya menetap di Bali maksimal satu tahun, berasal dari negara selain Indonesia, berusia 19-35 tahun, mahasiswa S1 maupun mahasiswa S2 serta belum menikah.

Teknik yang digunakan dalam pengambilan sampel ialah salah satu teknik dari nonprobability random sampling berupa purposive sampling, yaitu teknik pengambilan sampel yang digunakan dengan pertimbangan tertentu (Sugiyono, 2012). Teknik ini digunakan karena populasi penelitian merupakan populasi yang spesifik, sehingga pengambilan sampel dapat langsung dilakukan pada populasi spesifik dengan mempertimbangkan kriteria-kriteria pengambilan sampel yang ditetapkan peneliti.

Populasi subjek penelitian adalah sebesar 262 mahasiswa asing dari berbagai program studi di Universitas Udayana. Peneliti menggunakan rumus penentuan jumlah sampel dari Higgins, Kleinbaum, dan Miller (1985) untuk menentukan jumlah sampel minimal yang harus diambil sebagai subjek penelitian. Berdasarkan perhitungan jumlah sampel, didapatkan bahwa jumlah minimal sampel yang harus disertakan dalam penelitian adalah 135 orang. Peneliti mengambil sejumlah 150 sampel, tetapi terdapat 5 sampel yang gugur sehingga total sampel yang diikutsertakan dalam analisis adalah sebanyak 145 sampel.

\section{Tempat penelitian}

Responden dalam penelitian ini merupakan mahasiswa asing yang mengikuti program student exchange di Universitas Udayana. Mahasiswa asing yang diikusertakan sebagai responden dalam penelitian ini berasal dari program International Business Studies Networrk, Indonesian Language for Foreign Speakers, dan Bali International Program on Asian Studies. Pengambilan sampel penelitian dilakukan selama bulan November 2012 sampai Januari 2013. Sebelum melakukan penelitian, peneliti melakukan try out dengan mengambil 52 responden yang merupakan mahasiswa asing di Fakultas Kedokteran Universitas Udayana angkatan 2010 dan 2011 pada bulan November 2012.

\section{Alat ukur}

Alat ukur yang digunakan dalam penelitian ini adalah dengan menggunakan kuesioner. Variabel kepribadian diukur dengan menggunakan kuesioner yang sudah terstandarisasi yaitu The Big Five Inventory (John, Donahue, \& Kentle, 1991). Aitem dalam skala ini berjumlah 44 aitem dengan menggunakan skala Likert 5 poin (sangat tidak setuju - sangat setuju). Jenis data yang diperoleh ialah data interval. Varibel penyesuaian diri diukur dengan menggunakan kuesioner Sojourner Adjustment Measure (Pedersen, Neighbors,
Larimer, \& Lee, 2011) yang telah dimodifikasi oleh peneliti sesuai dengan karakteristik subjek penelitian. Aitem dalam skala ini berjumlah 24 aitem dengan menggunakan skala Likert 7 poin (sangat tidak setuju - sangat setuju). Jenis data yang diperoleh ialah data interval.

Sebelum alat ukur digunakan dalam melakukan penelitian dilaksanakan uji coba terlebih dahulu terhadap kuesioner. Uji coba yang dilakukan pada 52 subjek menyatakan bahwa validitas kuesioner The Big Five Inventory bergerak dari 0,309-0,810. Validitas aitem dalam The Big Five Inventory berada di atas nilai 0,3 sehingga seluruh aitem dalam kuesioner dinyatakan valid (Azwar, 2000). Reliabilitas kuesioner The Big Five Inventory adalah 0,946 yang berada di atas nilai maksimum 0,6 sehingga kuesioner dapat dinyatakan reliabel (Azwar, 2000).

Uji coba yang dilakukan pada kuesioner Sojourner Adjustment Measure menyatakan bahwa validitas aitem bergerak dari 0,109-0,673. Nilai validitas aitem dibawah 0,3 dinyatakan tidak valid, sehingga terdapat 4 aitem dari 24 aitem dalam Sojourner Adjustment Measure yang harus digugurkan sehingga total aitem yang valid adalah 20 aitem. Setelah 4 aitem digugurkan, validitas mengalami perubahan sehingga pergerakan validitas aitem adalah dari 0,335 - 0,705. Reliabilitas kuesioner Sojourner Adjustment Measure adalah 0,785 yang berada di atas nilai maksimum 0,6 sehingga kuesioner dapat dinyatakan reliabel (Azwar, 2000).

\section{Metode pengumpulan data}

Metode pengumpulan data yang digunakan dalam penelitian ini adalah dengan menggunakan dua kuesioner, yaitu kuesioner The Big Five Inventory untuk mengukur variabel kepribadian, serta kuesioner Sojourner Adjustment Measure untuk mengukur variabel penyesuaian diri. Data-data tambahan yang relevan digunakan dalam deskripsi data penelitian dicantumkan dalam personal information dari subjek penelitian.

Pengumpulan data dilakukan dengan menyebarkan kuesioner ke beberapa program studi di Universitas Udayana yang mengadakan program student exchange. Program studi yang menjadi tempat peneliti dalam menyebarkan kuesioner adalah International Business Studies Network, Indonesian Languange for Foreign Speakers, dan Bali International Program on Asian Studies. Sebelum kuesioner disebarkan, peneliti memberikan surat permohonan izin untuk melakukan penelitian kepada International Office of Udayana University serta masing-masing program studi tempat subjek penelitian menjalani studi. Setelah mendapat ijin, peneliti memberikan kuesioner kepada subjek dan kuesioner akan diambil kembali dalam jangka waktu satu minggu kemudian. Kuesioner yang disebar kembali seutuhnya, tetapi terdapat 5 kuesioner yang 
tidak lengkap sehingga harus dikeluarkan dari analisis data, sehingga total data yang diperoleh ialah sejumlah 145 .

\section{Teknik analisis data}

Analisis data dilakukan dengan menggunakan program SPSS 17.0 for windows. Secara spesifik, digunakan analisis parametrik menggunakan analisis korelasi parsial. Korelasi parsial berfungsi untuk mencari besarnya hubungan dan kontribusi dua atau lebih variabel bebas (X) secara simultan (bersama-sama) dengan variabel tergantung (Y). Korelasi parsial dilakukan untuk meihat hubungan masingmasing dimensi kepribadian The Big Five Personality dengan penyesuaian diri mahasiswa asing di Universitas Udayana.

Koefisien korelasi (r) memiliki harga $\mathrm{r}$ sebesar $-1 \square \mathrm{r} \square+1$. Apabila nilai $r=1$, artinya korelasinya sangat kuat, sedangkan apabila nilai $r=-1$, maka artinya korelasi antar variabel sangat lemah. Taraf signifikansi yang digunakan dalam analisis ini adalah 5\%. Apabila probablilitas kurang dari 0,05 maka korelasi antar variabel dapat dikatakan memiliki hubungan secara signifikan.

\section{HASIL PENELITIAN}

Sebelum melakukan analisis korelasi parsial, terdapat dua asumsi yang harus dipenuhi. Asumsi pertama yang harus dipenuhi adalah asumsi normalitas untuk membandingkan persebaran data dengan kurva distribusi normal. Apablila signifikansi lebih besar dari 0,05 atau 5\% maka data dapat dikatakan memiliki distribusi yang normal (Priyatno, 2008). Uji normalitas dilakukan dengan menggunakan KolmogorovSmirnov pada SPSS 17.0 for windows. Hasil pengujian dapat dilihat pada tabel berikut:

\begin{tabular}{lcc} 
& $\begin{array}{c}\text { Tabel 1 } \\
\text { Hasil Uji Normalitas }\end{array}$ \\
\hline & Kepribadian & Penyesuaian Diri \\
\hline Kolmogorov-Smirnov Z & 0,660 & 1,074 \\
$\begin{array}{l}\text { Asymp. Significant } \\
\text { (2-tailed) }\end{array}$ & 0,776 & 0,199 \\
\hline
\end{tabular}

Sebaran data pada variabel kepribadian memiliki nilai signifikansi dengan probabilitas (p) sebesar 0,776 atau memiliki probabilitas diatas 0,05 ( $\mathrm{p}>0,05)$. Hal ini menunjukkan bahwa sebaran data pada variabel kepribadian bersifat normal. Sebaran data pada variabel penyesuaian diri memiliki nilai signifikansi dengan probabilitas sebesar 0,199 atau memiliki probabilitas diatas $0,05(\mathrm{p}>0,05)$. Hal ini menunjukkan bahwa sebaran data pada variabel penyesuaian diri bersifat normal.

Asumsi kedua yang harus dipenuhi adalah asumsi linearitas untuk mengetahui apakah dua variabel memiliki hubungan yang linear atau tidak secara signifikan. Uji linearitas dalam penelitian menggunakan SPSS 17.0 for windows ialah dengan melihat nilai test for linearity pada taraf signifikansi 0,05. Hubungan linear yang signifikan terjadi apabila signifikansinya kurang dari 0,05 (Nurgiyanto, Gunawan, dan Marzuki, 2008). Hasil pengujian dapat dilihat pada tabel berikut:

Tabel 2

Hasil Uji Linearitas Kepribadian dan Penyesuaian Diri

\begin{tabular}{lclcc}
\hline & & F & Signifikansi \\
\hline BFI*SAM & Between Groups & (Combined) & 1,981 & 0,002 \\
& & Linearity & 42,553 & 0,000 \\
& & Deviation from linearity & 1,425 & 0,069 \\
\hline
\end{tabular}

Hasil pengujian menunjukkan bahwa hubungan kepribadian dan penyesuaian diri mahasiswa asing adalah linear karena memiliki probabilitas (p) sebesar 0,000 atau memiliki taraf signifikansi untuk linearitas lebih kecil dari $0,05$ ( $\mathrm{p}<0,05)$ sehingga dikatakan bahwa hubungan antara skor variabel kepribadian dan variabel penyesuaian diri telah menunjukkan adanya garis yang sejajar atau lurus. Berdasarkan uji normalitas dan uji linearitas yang telah dilakukan diperoleh hasil bahwa data penelitian bersifat normal dan linear sehingga analisis korelasi parsial dapat dilanjutkan.

Peneliti membedakan kategori dari masing-masing variabel dengan menggunakan rumus rentangan berdasarkan standar deviasi dan mean empiris dilihat dari kurva normal (Azwar, 2000). Kategorisasi yang dilakukan oleh peneliti terbagi kedalam 5 kategori, yaitu kategori sangat rendah, rendah, sedang, tinggi, dan sangat tinggi.

Berdasarkan rumus pengkategorian skor dari Azwar (2000), peneliti kemudian mengkategorikan variabel penyesuaian diri dan kelima dimensi dalam The Big Five Personality ke dalam lima kategori. Pengkategorian skor variabel kepribadian dan penyesuaian diri beserta frekuensi dan persentasenya akan dicantumkan dalam tabel-tabel dibawah ini :

\begin{tabular}{lllcc}
\multicolumn{5}{c}{ Tabel 3 } \\
& \multicolumn{3}{c}{ Kategorisasi Skor Dimensi Kepribadian Extraversion } \\
\hline Variabel & Rentang Nilai & Kategori Skor & Frekuensi & Persentase \\
\hline Extraversion & $\mathrm{x} \leq 22,24$ & Sangat Rendah & 8 & $5,5 \%$ \\
& $22,24<\mathrm{x} \leq 27$ & Rendah & 41 & $28,2 \%$ \\
& $27<\mathrm{x} \leq 31,78$ & Sedang & 61 & $42,1 \%$ \\
& $31,78<\mathrm{x} \leq 36,54$ & Tinggi & 28 & $14,5 \%$ \\
& $36,54<\mathrm{x}$ & Sangat Tinggi & 7 & $4,9 \%$ \\
\hline
\end{tabular}

Pada dimensi kepribadian extraversion, subjek penelitian sebanyak $42,1 \%$ berada pada kategori sedang. Subjek penelitian yang berada dalam kategori ekstrim diantaranya adalah 5,5\% subjek penelitian berada dalam kategori sangat rendah dan sebanyak 4,9\% subjek penelitian berada dalam kategori sangat tinggi.

Tabel 4

Kategorisasi Skor Dimensi Kepribadian Agreeableness

\begin{tabular}{lllcc}
\hline Variabel & Rentang Nilai & Kategori Skor & Frekuensi & Persentase \\
\hline Agreeableness & $\mathrm{x} \leq 26,14$ & Sangat Rendah & 12 & $8,3 \%$ \\
& $26,14<\mathrm{x} \leq 31,29$ & Rendah & 37 & $25,5 \%$ \\
& $31,29<\mathrm{x} \leq 36,43$ & Sedang & 60 & $41,4 \%$ \\
& $36,43<\mathrm{x} \leq 41,58$ & Tinggi & 29 & $20 \%$ \\
& $41,58<\mathrm{x}$ & Sangat Tinggi & 7 & $4,8 \%$ \\
\hline
\end{tabular}


Pada dimensi kepribadian agreeableness, subjek penelitian sebanyak $41,4 \%$ berada pada kategori sedang. Subjek penelitian yang berada dalam kategori ekstrim diantaranya adalah sebanyak $8,3 \%$ subjek penelitian berada dalam kategori sangat rendah dan sebanyak 4,8\% subjek penelitian berada dalam kategori sangat tinggi.

$$
\text { Tabel } 5
$$

Kategorisasi Skor Dimensi Kepribadian Conscientiousness

\begin{tabular}{lllcc}
\hline Variabel & Rentang Nilai & Kategori Skor & Frekuensi & Persentase \\
\hline Conscientiousness & $\mathrm{x} \leq 24,15$ & Sangat Rendah & 11 & $7,6 \%$ \\
& $24,15<\mathrm{x} \leq 29,4$ & Rendah & 36 & $24,8 \%$ \\
& $29,4<\mathrm{x} \leq 34,65$ & Sedang & 57 & $39,3 \%$ \\
& $34,65<\mathrm{x} \leq 40$ & Tinggi & 34 & $23,4 \%$ \\
& $40<\mathrm{x}$ & Sangat Tinggi & 7 & $4,8 \%$ \\
\hline
\end{tabular}

Pada dimensi kepribadian conscientiousness, subjek penelitian sebanyak 39,3\% berada pada kategori sedang. Subjek penelitian yang berada dalam kategori ekstrim diantaranya adalah sebanyak $7,6 \%$ subjek penelitian berada dalam kategori sangat rendah dan sebanyak $4,8 \%$ subjek penelitian berada dalam kategori sangat tinggi.

Tabel 6

Kategorisasi Dimensi Kepribadian Neuroticism

\begin{tabular}{lllcc}
\hline Variabel & Rentang Nilai & Kategori Skor & Frekuensi & Persentase \\
\hline Neuroticism & $\mathrm{x} \leq 22,04$ & Sangat Rendah & 14 & $9,6 \%$ \\
& $22,04<\mathrm{x} \leq 27$ & Rendah & 31 & $21,4 \%$ \\
& $27<\mathrm{x} \leq 31,77$ & Sedang & 62 & $42,7 \%$ \\
& $31,77<\mathrm{x} \leq 36,64$ & Tinggi & 34 & $23,4 \%$ \\
& $36,64<\mathrm{x}$ & Sangat Tinggi & 4 & $2,7 \%$ \\
\hline
\end{tabular}

Pada dimensi kepribadian neuroticism, subjek penelitian sebanyak $42,7 \%$ berada pada kategori sedang. Subjek penelitian yang berada dalam kategori ekstrim diantaranya adalah sebanyak 9,6\% subjek peneltian berada dalam kategori sangat rendah dan sebanyak 2,7\% subjek penelitian berada dalam kategori sangat tinggi.

Tabel 7

Kategorisasi Skor Dimensi Kepribadian Openness to New Experience

\begin{tabular}{lllcc}
\hline Variabel & Rentang Nilai & Kategori Skor & Frekuensi & Persentase \\
\hline Openness to new & $\mathrm{x} \leq 27,16$ & Sangat Rendah & 11 & $7,6 \%$ \\
experience & $27,16<\mathrm{x} \leq 33$ & Rendah & 42 & $29 \%$ \\
& $33<\mathrm{x} \leq 38,65$ & Sedang & 52 & $35,9 \%$ \\
& $38,65<\mathrm{x} \leq 44,4$ & Tinggi & 33 & $22,7 \%$ \\
& $44,4<\mathrm{x}$ & Sangat Tinggi & 7 & $4,8 \%$ \\
\hline
\end{tabular}

Pada dimensi kepribadian openness to new experience, subjek penelitian sebanyak $35,9 \%$ berada pada kategori sedang. Subjek penelitian yang berada dalam kategori ekstrim diantaranya adalah sebanyak $7,6 \%$ subjek penelitian berada dalam kategori sangat rendah dan sebanyak $4,8 \%$ subjek penelitian berada dalam kategori sangat tinggi.

Kepribadian subjek penelitian apabila dilihat dari masing-masing dimensi The Big Five Personaliy mengungkapkan bahwa kebanyakan subjek penelitian memiliki tingkat extraversion yang sedang $(42,1 \%)$, tingkat agreeableness yang sedang $(41,4 \%)$, tingkat conscientiousness yang sedang $(39,3 \%)$, tingkat neuroticism yang sedang $(42,7 \%)$, serta tingkat openness to new experience yang sedang $(35,9 \%)$. Sedangkan subjek penelitian dengan jumlah paling sedikit berada dalam kategorisasi ekstrim yaitu sangat tinggi adalah sebanyak sebesar 4,9\% extraversion, $4,8 \%$ agreeableness, 4,8\% conscientiousness, 2,7\% neuroticism, serta $4,8 \%$ openness to new experience.

Kategorisasi skor penyesuaian diri akan dijabarkan secara lebih terperinci pada tabel 8 dibawah ini:

Tabel 8

Kategorisasi Skor Penyesuaian Diri

\begin{tabular}{lllcc}
\hline Variabel & Rentang Nilai & Kategori Skor & Frekuensi & Persentase \\
\hline Penyesuaian Diri & $\mathrm{x} \leq 88,43$ & Sangat Rendah & 5 & $3,45 \%$ \\
& $88,43<\mathrm{x} \leq 101.85$ & Rendah & 53 & $36,55 \%$ \\
& $101,85<\mathrm{x} \leq 115,28$ & Sedang & 48 & $33,1 \%$ \\
& $115,28<\mathrm{x} \leq 128,72$ & Tinggi & 26 & $17,93 \%$ \\
& $128,72<\mathrm{x}$ & Sangat Tinggi & 13 & $8,96 \%$ \\
\hline
\end{tabular}

Dari kategorisasi skor yang dilakukan peneliti, persentase paling besar ditemukan pada kategori skor rendah, yang berarti bahwa sebanyak 36,55\% subjek penelitian berada pada kategori rendah. Sedangkan persentase paling kecil ditemukan pada kategori skor sangat rendah, yang berarti bahwa sebanyak 3,45\% subjek penelitian berada pada kategori sangat rendah. Tetapi sesuai dengan hasil mean empiris yang lebih besar dari mean teoritis, tingkat penyesuaian diri subjek tergolong tinggi yaitu sejumlah $60 \%$ subjek berada dalam kategori sedang sampai dengan kategori sangat tinggi.

Analisis korelasi parsial digunakan karena peneliti ingin mengetahui hubungan yang murni dari masing-masing dimensi kepribadian terhadap penyesuaian diri ketika dikontrol oleh dimensi kepribadian The Big Five Personality lainnya, yaitu dimensi extraversion, agreeableness, conscientiousness, neuroticism, dan openness to new experience. Hasil analisis korelasi parsial dijabarkan dalam tabel 9:

Tabel 9

Korelasi Parsial Dimensi-Dimensi Kepribadian dengan Penyesuaian Diri

\begin{tabular}{|c|c|c|}
\hline \multirow[t]{2}{*}{ Dimensi Kepribadian } & \multicolumn{2}{|c|}{ Penyesuaian Diri } \\
\hline & $\mathbf{R}$ & sig (1-tailed) \\
\hline Extraversion $(\mathrm{A}, \mathrm{C}, \mathrm{N}, \mathrm{O})$ & $-0,130$ & 0,062 \\
\hline Agreeableness $(\mathrm{C}, \mathrm{N}, \mathrm{O}, \mathrm{E})$ & 0,285 & 0,000 \\
\hline Consciountiousness $(\mathrm{N}, \mathrm{O}, \mathrm{E}, \mathrm{A})$ & 0,101 & 0,117 \\
\hline Neuroticism $_{(\mathrm{O}, \mathrm{E}, \mathrm{A}, \mathrm{C})}$ & $-0,017$ & 0,421 \\
\hline Openness to new experience $(\mathrm{E}, \mathrm{A}, \mathrm{C}, \mathrm{N})$ & 0,136 & 0,05 \\
\hline
\end{tabular}

( ) : variabel kontrol

Berdasarkan hasil analisis korelasi parsial yang dilakukan peneliti, didapatkan hasil bahwa dimensi kepribadian yang memiliki hubungan positif yang signifikan dengan penyesuaian diri ialah dimensi agreeableness dan openness to new experience. Dimensi kepribadian lainnya yakni dimensi extraversion, conscientiousness, dan neuroticism tidak memiliki hubungan yang signifikan dengan penyesuaian diri mahasiswa asing di Universitas Udayana karena memiliki probabilitas di atas 0,05 .

Dimensi agreeableness memiliki koefisien korelasi sebesar 0,285 dan signifikansi sebesar 0,000 ( $p<0,05)$ yang berarti bahwa dimensi agreeableness memiliki hubungan yang 
signifikan searah dengan penyesuaian diri ketika dikontrol dengan dimensi kepribadian lainnya secara simultan. Hubungan yang searah berarti semakin tinggi tingkat agreeableness yang dimiliki oleh mahasiswa asing, maka penyesuaian diri akan semakin baik.

Dimensi openness to new experience memiliki koefisien korelasi sebesar 0,136 dan signifikansi sebesar 0,05 ( $\mathrm{p}<0,05$ ) yang berarti bahwa dimensi openness to new experience memiliki hubungan yang signifikan dan searah dengan penyesuaian diri ketika dikontrol dengan dimensi kepribadian lainnya secara simultan. Hubungan yang searah memiliki makna bahwa jika tingkat openness to new experience mahasiswa asing semakin tinggi, maka akan diikuti pula dengan peningkatan penyesuaian diri.

Dimensi extraversion $(r=-0,131, \mathrm{p}>0,05)$, conscientiousness $(r=0,101, p>0,05)$ neuroticism $(r=-$ $0,017, \mathrm{p}>0,05)$ tidak memiliki hubungan yang signifikan dengan penyesuaian diri mahasiswa asing di Universitas Udayana. Hal ini berarti bahwa dimensi kepribadian extraversion, conscientiousness, dan neuroticism tidak dapat mempengaruhi proses penyesuaian diri mahasiswa asing di Bali.

Jadi, dimensi kepribadian yang memiliki hubungan positif yang signifikan dengan penyesuaian diri ialah agreeableness dan openness to new experience. Sementara tidak ditemukan adanya hubungan yang signifikan antara dimensi kepribadian extraversion, conscientiousness, dan neuroticism dengan penyesuaian diri mahasiswa asing di Universitas Udayana.

\section{PEMBAHASAN DAN KESIMPULAN}

Sebagaimana yang telah dikemukakan di atas, hasil penelitian ini menunjukkan bahwa terdapat hubungan yang signifikan antara dimensi kepribadian agreeableness dan openness to new experience dengan penyesuaian diri mahasiswa asing di Universitas Udayana. Sedangkan dimensi kepribadian extraversion, conscientiousness, dan neuroticism tidak memiliki hubungan yang signifikan dengan penyesuaian diri mahasiswa asing di Universitas Udayana.

Dimensi kepribadian extraversion pada subjek penelitian kebanyakan tergolong dalam kategori sedang $(42,1 \%)$. Berdasarkan hasil penelitian ini, extraversion tidak memiliki hubungan positif yang signifikan $(\mathrm{r}=-0,130, \mathrm{p}>$ $0,05)$ dengan penyesuaian diri.

Hubungan antara dimensi agreeableness dengan penyesuaian diri mahasiswa asing sesuai dengan penelitian yang dilakukan oleh Ward, Leong, dan Low (2004) yaitu dimensi kepribadian agreeableness dengan skor tinggi memiliki hubungan yang positif dengan penyesuaian diri psikologis dan sosiokultural mahasiswa asing. Dimensi kepribadian agreeableness diasosiasikan dengan kesehatan dan kesejahteraan psikologis, serta berperan penting dalam membangun hubungan yang baik dengan masyarakat lokal di negara tujuan mahasiswa asing (Ones \& Viswesvaran, 1997).

Mahasiswa asing dengan skor agreeableness yang tinggi akan memiliki kesejahteraan psikologis yang lebih tinggi juga dibandingkan dengan mahasiswa asing yang memiliki skor agreeableness rendah. Kesejahteraan psikologis yang baik mampu melancarkan proses penyesuaian diri mahasiswa asing. Individu dengan skor agreeableness yang tinggi juga dianggap mampu bersikap fleksibel dalam berinteraksi dengan masyarakat lokal. Hal itu adalah merupakan faktor penting dalam penyesuaian diri mahasiswa asing di negara tujuan. Interaksi sosial yang baik dengan masyarakat lokal mampu memberikan kepercayaan diri pada mahasiswa asing serta peningkatan pengetahuan akan budaya negara tujuan.

Mayoritas subjek penelitian $(41,4 \%)$ memiliki skor dalam kategori sedang pada dimensi kepribadian agreeableness. Akan tetapi, dari hasil analisis korelasi parsial didapatkan bahwa hubungan antara dimensi kepribadian agreeableness dengan penyesuaian diri lemah $(r=0,285)$. Koefisien determinasi (r2) sebesar 0,081 yang berarti bahwa dimensi kepribadian agreeableness hanya memiliki kontribusi sebesar $8,1 \%$ terhadap penyesuaian diri mahasiswa asing di Universitas Udayana.

Hal ini berarti bahwa dimensi kepribadian agreeableness sendiri tidak dapat menjamin penyesuaian diri yang baik, tetapi harus dilihat juga dari variabel-variabel lain yang mungkin berkaitan dengan penyesuaian diri mahasiswa asing. Variabel-variabel yang mungkin dapat mempengaruhi penyesuaian diri antara lain adalah usia, jenis kelamin, pengalaman tinggal di negara lain sebelumnya, adanya diskriminasi, kesulitan berbahasa, dan lain-lain.

Hubungan antara dimensi kepribadian extraversion tidak konsisten dari hasil penelitian satu dengan hasil penelitian lainnya. Dalam berbagai penelitian yang telah dilakukan, hubungan antara dimensi kepribadian extraversion dapat memiliki hubungan yang positif, negatif, bahkan tidak signifikan terhadap penyesuaian diri mahasiswa asing. Sedangkan pada peneltian ini ditemukan bahwa dimensi extraversion tidak memiliki hubungan yang signifikan dengan penyesuaian diri mahasiswa asing di Universitas Udayana.

Dimensi kepribadian extraversion dihubungkan dengan depresi, kondisi kesehatan yang buruk, rasa bosan serta frustrasi. Hubungan yang tidak signifikan antara dimensi kepribadian extraversion dengan penyesuaian diri juga dapat disebabkan oleh adanya perbedaan individu ketika berinteraksi dengan karakteristik budaya yang berbeda dengan budaya negara asal mahasiswa asing (Armes \& Ward, 2001), yang mungkin dapat menyebabkan stres.

Karakteristik dari individu yang memiliki skor extraversion yang tinggi antara lain ialah individu tersebut memiliki rasa kasih sayang yang besar, banyak bicara, 
menyenangkan, aktif, dan bersemangat (John, 1990; Costa \& McCrae, 1992). Hubungan yang tidak signifikan dapat disebabkan juga karena keaktifan mahasiswa asing dalam kehidupannya di Bali dimanifestasikan ke dalam hal lainnya yang lebih menyenangkan seperti bersosialisasi serta melakukan kegiatan yang menyenangkan seperti surfing, clubbing, dan lain-lain. Mahasiswa asing yang memiliki motivasi untuk menggunakan sebagian besar waktunya untuk berlibur di Universitas Udayana dalam periode pertukaran pelajarnya yang singkat akan lebih fokus untuk menikmati setiap waktunya sendiri sehingga memiliki implikasi terhadap proses penyesuaian diri yang dilakukan, dan secara tidak langsung akan menurunkan tingkat stres.

Dimensi kepribadian conscientiousness pada subjek penelitian kebanyakan berada dalam kategori sedang $(39,3 \%)$. Berdasarkan analisis korelasi parsial yang telah dilakukan peneliti, dimensi kepribadian conscientiousness tidak memiliki hubungan positif yang signifikan $(r=0,101, \mathrm{p}>0,05)$ dengan penyesuaian diri.

Karakteristik dari individu yang memiliki skor tinggi dalam dimensi kepribadian conscientiousness ialah teliti, tepat waktu, tekun, pekerja keras, dan ambisius (John, Donahue, \& Kentle, 1991; Costa \& McCrae, 1992). Tetapi mahasiswa pertukaran di Universitas Udayana lebih menggunakan waktunya untuk menikmati suasana di Bali dibandingkan dengan mengikuti proses pembelajaran yang ada di universitas. Alasan utama mahasiswa asing dalam memilih Bali sebagai negara tujuan pendidikan mereka adalah untuk dapat bersenang-senang seperti surfing, travelling, clubbing, dan lain-lain $(41,4 \%)$, diikuti oleh ketertarikan akan budaya Bali (14,5\%), ingin mendapatkan pengalaman baru dan bertemu dengan orang-orang baru (13,8\%), mempelajari Bahasa Indonesia (11,7\%), serta menikmati cuaca dan lingkungan di Bali (10,3\%). Sedangkan, alasan untuk memenuhi kewajiban akademis atau pendidikan yang ditemukan dalam data penelitian hanyalah sebesar 8,3\%. Maka dari itu, dimensi conscientiousness tidak memiliki hubungan yang signifikan dengan penyesuaian diri

Dalam analisis data yang dilakukan peneliti didapatkan hasil bahwa terdapat hubungan yang signifikan antara dimensi openness to new experience dengan penyesuaian diri mahasiswa asing di Universitas Udayana. Hasil dari penelitian ini selaras dengan penelitian yang dilakukan oleh O'Connor \& Paunonen (2007) yakni dimensi openness to new experience memiliki hubungan yang positif dengan penyesuaian diri mahasiswa asing, serta penelitian dari Kim (1988) yang menyatakan bahwa dimensi openness to new experience relevan terhadap penyesuaian diri.

Mahasiswa asing dengan skor openness to new experience yang tinggi akan lebih mudah menyesuaikan diri dengan lingkungan barunya, karena mahasiswa asing terbuka akan nilai-nilai, norma-norma, serta pengalaman baru yang ditemui di negara tujuan pendidikan mereka. Sikap terbuka terhadap pengalaman baru memudahkan mahasiswa asing untuk mempelajari serta mengenal lebih dalam mengenai budaya baru yang berbeda dengan negara asalnya. Apabila mahasiswa asing dapat menerima dengan baik berbagai perubahan budaya yang terjadi, maka proses penyesuaian diri mahasiswa asing akan berjalan dengan lancar.

Sebanyak $33,1 \%$ subjek penelitian memiliki skor dalam kategori sedang pada dimensi openness to new experience, akan tetapi hubungan antara openness to new experience dengan penyesuaian diri sangat lemah $(r=0,136)$ yang menunjukkan bahwa dimensi ini tidak dapat mempengaruhi penyesuaian diri mahasiswa asing secara langsung. Koefisien determinasi (r2) adalah 0,018 yang berarti bahwa dimensi kepribadian openness to new experience hanya memiliki kontribusi sebesar $1,8 \%$ terhadap penyesuaian diri mahasiswa asing di Universitas Udayana.

Dimensi kepribadian neuroticism pada subjek penelitian kebanyakan tergolong dalam kategori sedang $(42,7 \%)$. Berdasarkan hasil analisis korelasi parsial yang dilakukan, dimensi neuroticism memiliki hubungan yang tidak signifikan dengan penyesuaian diri $(r=0,017, \mathrm{p}>0,05)$. Dimensi neuroticism adalah dimensi kepribadian yang paling relevan dalam menunjukkan maladjustment pada individu dari segala usia (McCrae \& Costa, 2003). Akan tetapi, subjek penelitian ini mengalihkan rasa cemasnya dengan motivasi yaitu menikmati Bali selama menjalani periode pertukaran pelajar di Bali, sehingga tidak menampakkan usaha yang terlalu banyak untuk menyesuaikan diri di Universitas Udayana. Berdasarkan hasil preliminary study yang dilakukan sebelumnya, diketahui bahwa tuntutan bagi mahasiswa asing program pertukaran pelajar juga tidak terlalu berat, karena mahasiswa asing hanya menetap di Bali selama kurang dari enam bulan dan beban akademis tidak terlalu menyulitkan mahasiswa asing.

Berdasarkan deskripsi penelitian, didapatkan bahwa usia subjek berkisar antara 20 - 31 tahun dengan mayoritas subjek berusia 22 tahun (20\%), lamanya tinggal di Bali selama 4 bulan sampai satu tahun dengan mayoritas subjek tinggal selama 4 bulan di Bali $(33,3 \%)$, memiliki kelancaran berbahasa Inggris yang baik yaitu skor 8 dari $10(37,2 \%)$ dan kelancaran berbahasa Indonesia yang rendah yaitu skor 2 dari 10 (42,1\%), serta sebanyak 74,5\% subjek membiayai pendidikannya di Universitas Udayana dengan biaya pribadi. Hal ini sesuai dengan hasil penelitian Sumer, Poyrazli, dan Grahame (2008) yaitu semakin muda usia seseorang, semakin lama seseorang tinggal di negara tujuan, dan semakin lancar menggunakan Bahasa Inggris, maka penyesuaian diri akan berlangsung semakin baik. Individu yang berusia lebih muda lebih terbuka dalam mencoba hal-hal baru dan bersikap lebih fleksibel dibandingkan dengan individu yang berusia lebih tua. Semakin lama individu tinggal di negara tujuan akan membuat 
individu terbiasa dengan budaya dan norma-norma baru yang ditemui di negara tujuan. Penggunaan Bahasa Inggris yang baik juga dapat meningkatkan kuantitas dan kualitas komunikasi individu dengan individu lainnya, baik mahasiswa asing lain, mahasiswa dari Indonesia maupun masyarakat lokal sehingga proses penyesuaian diri akan berjalan dengan lebih lancar.

Banyaknya variabel lain yang berkontribusi pada penyesuaian diri mahasiswa asing menegaskan bahwa variabel kepribadian saja tidak dapat mempengaruhi penyesuaian diri mahasiswa asing secara langsung. Pengetahuan, sikap, serta kepribadian yang dimiliki oleh mahasiswa asing memiliki hubungan secara berbeda-beda terhadap berbagai aspek dalam kepribadian (Armes \& Ward, 2001).

Penyesuaian diri subjek dalam penelitian ini tergolong tinggi yaitu sebesar $61,34 \%$ yang tersebar dari kategori sedang sampai dengan kategori sangat tinggi. Selain itu, setiap dimensi kepribadian pada subjek penelitian juga tergolong memiliki skor yang cukup tinggi dan berada di kategori skor sedang sampai dengan sangat tinggi.

Berdasarkan seluruh hasil analisis yang telah dilakukan oleh peneliti, maka dimensi kepribadian yang memiliki hubungan dengan penyesuaian diri mahasiswa asing ialah dimensi kepribadian agreeableness, kemudian diikuti dengan dimensi kepribadian openness to new experience. Semakin tinggi skor individu pada dimensi kepribadian agreeableness dan openness to new experience maka semakin baik pula penyesuaian mahasiswa asing di Bali.

Sedangkan dimensi kepribadian lainnya, yaitu dimensi kepribadian extraversion, conscientiousness, serta neuroticism tidak memiliki hubungan yang signifikan dengan penyesuaian diri mahasiswa asing. Tingginya skor individu dalam dimensi kepribadian extraversion dan conscientiousness tidak memiliki hubungan dengan seberapa baiknya penyesuaian diri yang dilakukan oleh mahasiswa asing di Bali. Rendahnya skor individu dalam dimensi neuroticism tidak memiliki hubungan dengan seberapa sulitnya penyesuaian diri yang dilakukan oleh mahasiswa asing di Bali.

Dimensi kepribadian The Big Five Personality bukan satu-satunya variabel yang dapat mempengaruhi penyesuaian diri mahasiswa asing di lingkuungan barunya. Terdapat pula variabel lain yang dapat mempengaruhi penyesuaian diri mahasiswa asing, yaitu tuntutan akademis, tantangan penyesuaian diri, permasalahan bahasa, usia, jenis kelamin, lamanya tinggal di negara tujuan, dukungan sosial, perbedaan budaya negara asal dengan negara tujuan (cultural distance) serta motivasi untuk berprestasi.

Saran yang dapat peneliti berikan yaitu bagi mahasiswa asing agar meningkatkan kemampuan Bahasa Inggris dan Bahasa Indonesia serta mengikuti berbagai kegiatan akademis maupun non-akademis; bagi pihak universitas agar mengembangkan program pre-departure untuk mengenalkan mahasiswa asing pada sistem perkuliahan, kemampuan berkomunikasi, kehidupan masyarakat Bali, dan budaya di Bali serta membuat program pendampingan mahasiswa asing oleh mahasiswa dari Indonesia; serta bagi peneliti selanjutnya agar menggunakan mix-methods research, meneliti variabel lain yang mungkin memiliki hubungan dengan penyesuaian diri, dan memperluas cakupan populasi agar jumlah subjek penelitian semakin banyak dan meningkatkan kemampuan generalisasi hasil penelitian.

\section{DAFTAR PUSTAKA}

Al-Sharideh, K. A., \& Goe, W. R. (1998). Ethnic communities within the university: An examination of factors influencing the personal adjustment of international students. Research in Higher Education, 39(6), 669-725.

Armes, Kathryn., \& Collen Ward. (2001). Cross-Cultural Transitions and Sojourner Adjustment in Singapore. The Journal of Social Psychology, 129(2), 273-275.

Atwater, Eastwood. (1983). Psychology of Adjustment: Personal growth in a changing world (2nd ed.). New Jersey: Prentice-Hall Inc.

Azwar, S. (2000). Penyusunan Skala Psikologi. Yogyakarta: Pustaka Pelajar.

Azwar, S. (2010). Reliabilitas dan Validitas. Yogyakarta: Pustaka Pelajar.

Bektas, Yelda., Ayhan Demir, \& Randall Bowden. (2009). Psychological Adaptation of Turkish Students at U.S. Campuses. International Journal Adv Counselling, 31, 130143.

Berry, J. W. (1997). Immigration, acculturation, and adaptation. Applied Psychology: An International Journal of Psychology, 12, 277-297.

Bochner, S. (1982). The social psychology of cross-cultural relations. In S. Bochner (Ed.), Cultures in contact: Studies in crosscultural interaction (pp. 5-44). Oxford: Pergamon.

Boediono., \& Koster, W. (2004). Teori dan Aplikasi Statistika dan Probabilitas. Bandung: PT Remaja Rosdakarya.

Burger, Jerry M. (2008). Personality (7th Ed.). Belomont: Wadsworth.

Chaplin, W.F., John, O.P., \& Goldberg, L. R. (1988). Conceptions of states and traits: Dimensional attributes with ideals as prototypes. Journal of Personality and Social Psychology, 54, 541-557.

Church, A. (1982). Sojourner Adjustment. Psychological Bulletin, 91, 540-572. 
Costa, P.T., \& McCrae, R.R. (1985). The NEO Personality Inventory manual. Odessa, FL: Psychological Assesment Resources.

Costa, P.T., \& McCrae, R.R. (1992). NEO PI-R Professional manual. Odessa, FL: Psychological Assesment Resources.

Costa, P.T., \& McCrae, R.R. (2003). Personality in Adulthood: A Five-Factor Theory Perspective (2nd Ed.). London: The Guilford Press.

De Raad, B., Perugini, M., Hrebickova, M., \& Szarota, P. (1998). Lingua franca of personality: Taxonomies and structures based on the psycholexical approach. Journal of CrossCultural Psychology, 29, 212-232.

Feist, Jess \& Gregory J. Feist. (2009). Theories of Personality (7th Ed.).Singapore: McGraw-Hill.

Furnham, Adrian \& Stephen Bochner. (1986). Culture Shock: Psychological reactions to unfamiliar environments. London: Routledge.

Galchenko, Irina., \& Fons J.R. van de Vijver. (2007). The role of perceived cultural distance in the acculturation of exchange students in Russia. International Journal of Intercultural Relations, 31, 181-197.

Ghozali, Imam. (2002). Aplikasi Analisis Multivariate dengan Program SPSS. Semarang: Badan Penerbit Universitas Diponegoro.

Goldberg, L.R. (1981). Language and individual differences: The search for universals in personality lexicons. In L. Wheeler (Ed.), Review of personality and social psychology, (Vol. 2, pp. 141-165). Beverly Hills, CA: Sage.

Higgins, JE \& Kleinbaum, AP. (1985). International to Randomized Clinical Trials with an Emphasis on Contraceptive Research. Family Health International. 25-30.

Hogan, R. (1986). Hogan Personality Inventory manual. Minneapolis, MN: National Computer Systems.

James, Susan., John Hunsley, Geoffrey S. Navara, \& Melanie Alles. (2004). Marital, psychological, and sociocultural aspects of sojourner adjustment: expanding the field of enquiry. International Journal of Intercultural Relations, 28, 111126.

John, O.P. (1990). The "Big Five" factor taxonomy: Dimensions of personality in the natural language amd in questionnaires. In L. A. Pervin (Ed.), Handbook of Personality: Theory and research (pp. 66-100). New York: Guilford Press.

John, O.P., Donahue, E.M., \& Kentle, R.L. (1991). The Big Five Inventory---- Versions 4a and 54. Berkeley, CA: University of California, Berkeley, Institute of Personality and Social Research.
Kashima, Emiko S., \& Evelyn Loh. (2006). International students' acculturation: Effects of international, conational, and local ties and need for closure. International Journal of Intercultural Relations, 30, 471-485.

Kim, S.C. (1988). Young Korean Students in the United States. In J.C.H. Lin (Ed.), In Pursuir of education: Young Asian Students in the United States (pp. 44-54). CA: Pacific Asia Press.

Kuntjojo. (2009). Psikologi Kepribadian. Kediri: Universitas Nusantara PGRI.

Kuo, Ben C.H., \& Gargi Rysircar. (2006). An exploratory study of cross-cultural adaptation of adolescent Taiwanese unaccompanied sojourners in Canada. International Journal of Intercultural Relations, 30, 159-183.

Lin, J.G., \& Yi, J.K. (1997). Asian international students' adjustment: Issues and program suggestions. College Students Journal, 31(4)5, 473-485.

Misra, M. Crist., \& C. J. Burant. (2003). Relationship among life stress, social support, academic stressors, and reactions to stressors of international students in the United States. International Journal of Stress Management (10), 137-157.

Nurgiyanto, Burhan., Gunawan, dan Marzuki. (2009). Statistik Terapan Untuk Penelitian Ilmu-Ilmu Sosial. Yogyakarta: Gadjah Mada University Press.

Nursalam. (2008). Konsep dan Penerapan Metodologi Penelitian Ilmu Keperawatan. Jakarta: Salemba Medika.

O’Connor, Melissa C., \& Sampo V. Paunonen. (2007). Big Five Personality predictors of post-secondary academic performance. Personality and Individual Differences, 43, 971-990.

Oberg, K. (1960). Culture shock: Adjustment to new cultural environments. Practical Anthropology, 7, 177-182.

Ones, D.S., \& Viswesvaran, C. (1997). Personality determinants in the prediction of aspects of expatriate job success. In Z Aycan (Ed.), New approaches to employee management: Vol.4. Expatriate management: Theory and research (pp. 63-92). Stamford, CT: JAI Press.

Paige, R.M. (1990). International students: Cross-cultural psychological perspectives. In R.W. Brislin (Ed.), Applied cross-cultural psychology: Cross-cultural research and methodology series, 14, 367-382.

Pedersen, Paul. (1995). The Five Stages of Culture Shock: Critical Incidents around the World. Westport, CT: Greenwood Press. 
Pedersen, Eric R., Clayton Neighbors, Mary E. Larimer, \& Christine M. Lee. (2011). Measuring Sojourner Adjustment among American students studying abroad. International Journal of Intercultural Relations, 35, 881-889.

Poyrazli, Senel., Rajat K. Thukral, \& Erdinc Duru. (2010). International students' race-ethnicity, personality and acculturative stress. International Journal of Psychology and Counseling, 2(2), 25-32.

Priyatno, D. (2008). Mandiri Belajar SPSS. Yogyakarta: Mediakom.

Riduwan \& Sunarto. (2010). Pengantar Statistika Untuk Penelitian: Pendidikan, Sosial, Komunikasi, Ekonomi, dan Bisnis. Bandung: CV Alfabeta.

Srividhya, V. (2007). Mental Health and Adjustment Problems of Students of Students of Navodhaya, Central and State Schools. Dharwad: University of Agricultural Sciences.

Sugiyono. (2012). Metode Penelitian Kuantitatif, Kualitatif, dan Kombinasi (Mix Methods). Bandung: CV Alfabeta.

Sumer, Seda., S. Poyrazli, \& K. Grahame. (2008). Predictors of depression and anxiety among international students. Journal of Counseling and Development, 86(4), 429-437.

Sumer, Seda. (2009). International Students' Psychological and Sociocultural Adaptation in the United States. Counseling and Psychological Services Dissertation, Paper 34, 1-74.

Tomich, J.J. McWhirter \& M. U. A. Darcy. (2003). Personality and international students' adaptation experience. International Education, 33(1), 22-39.

Vansteenskiste, Maarten., Willy Lens, \& Bart Soenens. (2006). Autonomy and Relatedness among Chinese Sojourners and Applicants: Conflictual or Bebast Predictors of Well-Being and Adjustment?. Motiv Emot, 30, 273-282.

Verbik, L. \& Lasanowski, V. (2007). International Student Mobility: Patterns and Trends. London: Observatory of Borderless Higher Education.

Ward, C., \& Searle, W. (1991). The impact of value discrepancies annd cultural identity on psychological and socio-cultural adjustment of sojourners, International Journal of Intercultural Relations, 15, 209-225.

Ward, C., Berno, T., \& Main, A. (2002). Can the Cross-cultural Adaptability Inventory predict sojourner adjustment? In P. Boski, F.J.R. van de Vijver, \& A.M. Chodnicka (Ed.), New directions in cross-cultural psychology (pp. 409-423). Warsaw: Polish Psychological Associations.

Ward, C., Leong, C.H., \& Low, M. (2004). Personality and sojourner adjustment: An exploration of the Big Five and the cultural fit proposition. Journal of Cross-Cultural Psychology, 35, 137-151.

Yusoff, Yusliza Mohd. \& Shankar Chelliah. (2010). Adjustment in International Students in Malaysian Public University. International Journal of Innovation, Management and Technology, 1(3), 275-278.

Zhou, Yuefang., Divya Jindal-Snape, Keith Topping, \& John Todman. (2008). Theoretical models of culture shock and adaptation in international students in higher education. Studies in Higher Education, 33, 63-75. 